\title{
EL CUENTO ROMÁNTICO EN TRES REVISTAS DE LA DÉCADA DE 1840: EL LABERINTO (1843- 1845), REVISTA LITERARIA DEL ESPAÑOL (1845- 1846) Y EL SIGLO PINTORESCO (1845-1848)
}

\author{
Borja Rodríguez Gutiérrez \\ Universidad de Cantabria
}

\begin{abstract}
During the decade of 1840 the romantic spanish short story is going to follow the trends that had developed in the magazine representative of the conservative romanticism, the Semanario Pintoresco Español, and not those who existed in another great magazine of the movement, El Artista. The article does a brief revision of the history of the spanish short story in the first half of the 19th century, examines the main characteristics of the Semanario Pintoresco Español and of El Artista and finally it examines the stories published in three magazines: El Laberinto, Revista literaria de El Español and El Siglo Pintoresco, stops to come to the conclusion from that three magazines supports the characteristics of the stories aprecidos in the Semanario Pintoresco Español.
\end{abstract}

\section{El CUENTO ROMÁNTICO ANTES DE LA DÉCADA DE 1840.}

En la evolución histórica del cuento romántico, la década de 1840 significa la consolidación de una serie de características que se habían originado en la década anterior y la desaparición de otras que también habían comenzado a manifestarse entre 1830 y 1840. Estas tendencias se pueden ejemplificar con claridad en dos revistas básicas del Romanticismo español: El Artista y el Semanario Pintoresco Español. Sería la tendencia que el Semanario representa la que continuaría durante los años siguientes como se puede ver en tres revistas muy representativas de la década de 1840: El Laberinto, La Revista literaria de El Español y El Siglo Pintoresco. Pero los orígenes de la narración breve romántica eran anteriores y habían ya comenzado a producirse en España a finales del siglo XVIII $^{1}$.

\subsection{Breve reseña histórica}

En los últimos años del siglo XVIII aparecen las primeras muestras del cuento literario español. La prensa naciente de por entonces incorpora la narración breve a sus páginas porque se ajusta a la perfección a las necesidades de las publicaciones periódicas. De esta

\footnotetext{
${ }^{1}$ Para una historia detallada de la evolución histórica del cuento en los finales del XVIII y principios del XIX véase Rodríguez Gutiérrez, 2004. Para la historia de la prensa española en esos años Gómez Aparicio, 1967; Seoane, 1977; Sánchez Aranda y Barrera, 1992; Fuentes y Fernández Sebastián, 1997.
} 
forma cuento y periodismo inician una estrecha relación que a la altura de 1850 se ha cimentado y solidificado.

En los primeros años del siglo nos encontramos con iguales características. Las revistas que se publican en estos años (Correo de Sevilla, Memorial Literario, Minerva o el Revisor General) no se diferencian en su intención y contenidos de las que habían aparecido antes de 1800: los cuentos de esos años son, por lo tanto, una prolongación de las tendencias dieciochescas.

La Guerra de la Independencia y el reinado de Fernando VII constituyen un frenazo brusco y evidente al desarrollo de la narración breve. La progresiva influencia en el reino de María Cristina, el nacimiento de Isabel II y el gradual distanciamiento del rey de su hermano Carlos y de los elementos mas intransigentes de la reacción española hace que se produzca una tímida apertura política, que vuelve a permitir la publicación de la prensa. Una prensa que inicia su nueva andadura con más censuras y vigilancias que en las Cortes o en el Trienio, y que por lo tanto prefiere dejar de lado la política y buscar otro tipo de público y de mercado. Es en este momento cuando la prensa regresa a la sociedad española ya para quedarse. Y con ella regresa el cuento, iniciándose así una etapa de vertiginoso florecimiento y expansión.

Es imposible no sentir asombro ante el desarrollo de la prensa española en los años que van de 1830 a 1850. En esos años pasamos de una situación en la que un puñado de arrojados periodistas malviven a base de ofrecer al público sus producciones periódicas realizadas muchas veces de forma individual, a una nueva en la que una serie de empresas periodísticas establecidas y consolidadas desarrollan su actividad con un indudable beneficio económico (pensemos, por ejemplo, en los últimos contratos de Larra). Además de Fígaro se hacen presentes en la sociedad literaria española muchos nombres de periodistas: Ramón de Mesonero Romanos, José María Carnerero, Andrés Borrego, Modesto Lafuente Fray Gerundio, Santos López Pelegrín Abenámar, Antonio María Segovia El Estudiante, Ángel Fernández de los Ríos, Francisco Navarro Villoslada, Joaquín Francisco Pacheco.... Pasamos de dos publicaciones periódicas en Madrid en 1830 a más de cien en 1850. Y en lo que se refiere al cuento pasamos de publicaciones que insertan algún cuento entre noticias, informaciones sobre el precio de los garbanzos y las lentejas, versos de toda índole e incesantes noticias laudatorias sobre la Reina Gobernadora (Cartas Españolas) a revistas como el Museo de las Familias en la que los cuentos ocupan la mayor parte de su contenido.

Las temáticas más frecuentadas son uno de los elementos claves del cambio entre el primer período que hemos mencionado (1800-1808) y el tercero (1831-1850). En los primeros años nos encontramos casi exclusivamente con cuatro grupos de temas: los cuentos morales $(59,38 \%)$, los de aventuras $(18,75 \%)$, históricos $(12,50 \%)$ y de amor $(9,38 \%)$. En los últimos veinte años de la cincuentena, como ya hemos visto, se abre el abanico de posibilidades temáticas y nos encontramos con los histórico-legendarios $(38,24 \%)$, de amor $(16,58 \%)$, humorísticos $(14,71 \%)$, morales $(8,82 \%)$, fantásticos $(8,02 \%)$, aventuras $(5,08 \%)$ y costumbristas $(2,94 \%)$. Y no solamente esta apertura de 
temas; aparte de todos estos relatos pueden encontrarse algunos que podrían calificarse de populares, trágicos, psicológicos o religiosos ${ }^{2}$.

En el grupo de los cuentos histórico-legendarios reúno todos los relatos que tienen una ambientación en el pasado sin considerar la autenticidad o no de los hechos históricos que retratan. Quedan fuera de esta categoría los cuentos de ambiente histórico con elementos fantásticos que quedan incluidos en el grupo de los cuentos fantásticos.

Como cuentos fantásticos entiendo todos aquellos que incorporan elementos de fantasía, bien sea humorística, popular, terrorífica o religiosa. También incluyo aquí aquellos cuentos que mantienen la presencia de la fantasía a lo largo del relato, aunque la explicación final de los hechos sea plenamente realista.

Los cuentos humorísticos son aquellos en los que, a pesar de la presencia de elementos morales, satíricos o costumbristas (muy frecuentes) la idea principal del relato es la de divertir al lector.

Como cuentos costumbristas considero a los que utilizan la peripecia argumental para presentar un hecho curioso o una actividad propia de un ambiente determinado o de un lugar concreto. Si bien generalmente estos cuentos llevan añadida una carga satírica y humorística, en ellos prima la pintura y la presentación de ambientes, lugares, acciones y personajes sobre el humor o sobre la intención satírica del autor.

Los cuentos de amor son historias de época contemporánea centrados en la peripecia amorosa de una pareja o parejas.

El tema moral en los cuentos de estos años aparece con frecuencia. Pero entiendo que en los cuentos morales la intención moral prevalece sobre cualquier otra faceta, incluso sobre la correcta construcción del cuento. La forma queda en general subordinada a la intención moralizadora del autor.

Cuento de aventuras es un relato de ambiente contemporáneo que busca presentar una historia sugerente y novedosa, en la que la sorpresa y el interés destaquen por encima de todo.

Formalmente los cuentos están caracterizados por la presencia de un narrador con absoluto dominio sobre la trama, un destinatario que es el propio lector, y una ordenación cronológica en la que predomina una estructura lineal con una serie de escenas con una fuerte carga dramática que constituyen el grueso del relato. Es bastante frecuente la presentación del relato mediante un marco o introducción.

Domina de forma absoluta el narrador en tercera persona omnisciente que conoce todos los pensamientos de los personajes, sus pasados y sus destinos y que hace indicaciones sobre ello. Cuando el narrador es en primera persona el relato está, casi siempre, contado desde un momento posterior a los hechos y por un personaje que conoce a la perfección la historia, antecedentes y consecuencias, y que por lo tanto se encuentra en una situación muy semejante al narrador omnisciente a propósito de los hechos que cuenta.

Estos narradores tienen muchos puntos de contacto con el narrador de la literatura costumbrista. Por lo tanto, de la misma forma que hace éste, se dirigen con frecuencia al

\footnotetext{
${ }^{2}$ Véase B. Rodríguez Gutiérrez (2003).
} 
lector, de forma explícita, para hacerle indicaciones, ofrecerle consejos, señalarle las conclusiones que debe sacar del cuento, llamar la atención sobre los puntos importantes, etc. El lector es el destinatario principal del cuento y el narrador lo tiene presente como un elemento más de la historia, produciéndose en muchos de los relatos una suerte de diálogo entre narrador y lector.

El tiempo de estos relatos es un tiempo lineal en el que el orden lógico y cronológico es elemento fundamental de la obra. Los autores románticos hacen una selección de acontecimientos a la hora de relatar el cuento y concentran la mayor parte de su historia en unas pocas escenas, reduciendo al máximo, o eliminando, los nexos intermedios.

$\mathrm{Si}$ tuviéramos que describir el cuento «tipo» de los años 1831-1850 (independientemente del tema), diríamos que es un relato con narrador omnisciente $(78,35 \%)$, los diálogos recogidos en estilo directo $(76,02 \%)$, con una ordenación temporal estrictamente cronológica $(78,77 \%)$, estructurado en una serie de escenas con importante carga dramática $(61,43 \%)$, y en el que el asunto fundamental es la evolución del personaje central $(90,91 \%)$, bien sea en un proceso de superación $(44,67 \%)$ o degradación $(55,33 \%)$ : «cuento dramatizado».

Para el desarrollo de esta modalidad los autores incorporan buena parte de los recursos teatrales: preponderancia de los diálogos sobre el narrador, utilizándose las palabras de los personajes para informar al lector de los pormenores de la acción, separación tajante de las escenas y eliminación de elementos intermedios buscando efectos de bajadas de telón, monólogos «operísticos» de los personajes en momentos culminantes de la acción, etc.

Del análisis de estos relatos llaman la atención algunos elementos: el antirromanticismo, el extrañamiento temporal, el exotismo geográfico, la violencia, el recurso del misterio personal, el erotismo y la figura del artista.

El antirromanticismo es una constante y aparece desde el inicio de este período, encontrándonos con relatos antirrománticos ya en El Vapor (1833) y en El Correo de las Damas (1834). Este antirromanticismo adopta dos formas básicas: la denigración de lo romántico centrada en personajes que se ponen en ridículo por influencia de la moda romántica, y el ataque a la literatura romántica como factor de corrupción moral de sus lectores, que les lleva a la locura, la prostitución o el suicidio. Uno de los elementos más criticados del romanticismo es el menosprecio que se hace a la autoridad paterna en pro de un amor libre, y buena parte de los relatos antirrománticos están dedicados a ensalzar esta autoridad paterna.

El alejamiento temporal, como era de esperar, es muy frecuente en los cuentos románticos y la Edad Media es la época preferida no sólo en los relatos históricos sino también en los fantásticos. Esta preferencia por la ambientación histórica conlleva la presentación del castillo como escenario favorito de los autores románticos; la abundante presencia en estos relatos de escenas de batallas y combates individuales y la presentación de una gran mayoría de ambientes y personajes aristocráticos sobre los populares.

El exotismo geográfico resulta muy limitado y poco cultivado por los autores, y los pocos que se detienen en la presentación de ambientes distintos (Estébanez Calderón, Roca de Togores) se inclinan decididamente por la España Árabe.

La violencia está omnipresente en la narración breve de las revistas románticas: el progresivo maniqueísmo de los relatos de ambiente histórico lleva a resoluciones de la 
trama mediante combates, y para la presentación del villano siempre se recurre a los crímenes por él cometidos.

El amor prohibido es el conflicto básico de muchos cuentos románticos. Durante el transcurso de estos veinte años la reacción de las corrientes más conservadoras del romanticismo hispano queda muy patente en la resolución del conflicto, y de los enamorados que perecen víctimas de la sociedad o de la opresión paterna, o de la injusticia divina o de las tres cosas a la vez como encontramos en El Artista, pasamos a historias en las que el sometimiento de los jóvenes a la autoridad de los padres y el seguimiento estricto de sus órdenes constituyen el modo ideal de llegar a un final feliz y de unión entre los enamorados.

Los protagonistas de los cuentos muchas veces están presentados como personajes misteriosos y de la resolución de este misterio deviene el transcurso del relato. El misterio puede estar motivado por un personaje que regresa en busca de una venganza o castigo, o provenir de un origen desconocido para el mismo personaje: situaciones que también podemos encontrar en el teatro y en la novela romántica.

El erotismo es otro de los elementos que se echa de ver en seguida en los cuentos. Asociado de modo exclusivo a la presentación de la figura femenina, se centra en dos prototipos femeninos: la mujer rubia y pálida, vestida de blanco, pura e inocente, absolutamente pasiva tanto en cuanto personaje del relato como en actitud amorosa, y la mujer morena, vestida de fuertes colores, de actitud impúdica, malvada, y personaje activo en el relato y activo en el amor. Estas dos figuras se repiten a lo largo de toda la cuentística romántica. La descripción detallada de ambos prototipos es muy abundante. Con cierta frecuencia la protagonista pálida está también enferma y se percibe en muchos relatos un erotismo del dolor y de la enfermedad.

El artista es la figura preferida de los escritores románticos. En los cuentos aparece en múltiples ocasiones y constituye un irresistible atractivo para los autores la presentación de artistas desgraciados, sufrientes e ignorados. Pero la reacción conservadora que desde las páginas de las revistas se manifiesta en el cuento hace evolucionar esta figura y del artista maltratado por la vida e ignorado por la sociedad de los primeros cuentos pasamos en seguida a un artista que sufre por un inexplicada «maldición del genio», sin que en estos casos tenga la sociedad responsabilidad ninguna en el padecimiento del artista. Cuando van avanzando los años aparecen otro tipo de relatos sobre el artista que van ganado presencia: la historia de un artista pobre que gracias a su trabajo y talento consigue el éxito y el reconocimiento de la sociedad.

En 1835 aparece El Artista, bajo la dirección de dos jóvenes de 20 años. Eugenio de Ochoa y Federico de Madrazo; en 1836 el Semanario Pintoresco Español, que pilotaba un Ramón de Mesonero Romanos, que ya contaba por entonces con treinta y tres años. Estas dos revistas son muy diferentes en sus propuestas, en sus intenciones y en la aceptación pública que tuvieron. No hace falta comentar la enorme diferencia que hay entre los quince meses de vida de la revista de Ochoa y Madrazo y los veintiún años que se prolongó la publicación de la Enciclopedia Popular de Recreo, subtítulo de la revista fundada y dirigida, hasta 1842, por El Curioso Parlante.

En cuanto a las narraciones que se publicaron en ambas revistas hay también grandes diferencias. Las tres revistas que vamos a analizar en este artículo van a seguir la senda 
marcada por el Seminario Pintoresco Español y no por El Artista. Camino que ya habían seguido otras revistas en la década de 1830 , como hemos analizado en un artículo anterior ${ }^{3}$.

\subsection{El Artista}

El Artista tuvo, desde el principio, al cuento como uno de sus elementos fundamentales: 24 relatos en quince meses de vida. Publicaron en él cuentos Eugenio de Ochoa (6 relatos: «Los Dos Ingleses», «El Castillo del Espectro», «Luisa», «Ramiro», «Zenobia»y «Stephen»), José Bermúdez de Castro (3: «Los Dos Artistas», «Alucinación!!!» e «Historia de la muy noble y estimada señora Leonor Garavito»), José Augusto de Ochoa (3. «Beltrán», «La Peña del Prior» y «El Torrente de Blanca. Leyenda del siglo XIII»), Pedro de Madrazo (2: «Alberto Regadón» y «Yago Yasch»), Jacinto de Salas y Quiroga (2: «1532»y «La Predicción»), y un relato cada uno Luis González-Bravo («Abdhul-Adehl o el Mantés»), José Negrete, Conde de Campo-Alange («Pamplona y Elizondo»), M.A. Conde Duque de Lara («Arindal»), Fernán Caballero (con la firma de C.B.) («La Madre o el Combate de Trafalgar»), José Zorrilla («La Mujer Negra o Una Antigua Capilla de Templarios») y José de Espronceda («La Pata de Palo»). Además dos relatos anónimos: «La Constante Cordobesa» y «Lo que vio el pintor Wildherr en un antiguo castillo de la Selva Negra».

Una lista abundante de nombres importantes del romanticismo, aunque los relatos más relevantes de la revista son, sin duda, los dos de Pedro de Madrazo ${ }^{4}$ («Yago Yasch» y «Alberto Regadón») y «Pamplona y Elizondo» el único cuento que escribió el Conde de Campo-Alange, muerto muy joven en la guerra carlista, a quien dedicara Larra una sentida elegía.

Se ha discutido mucho sobre El Artista y sobre su importancia en el movimiento romántico y sobre si se trata de una revista representativa o no del romanticismo español. Por nuestra parte, si reducimos la respuesta al ámbito del relato breve, tenemos que decir que es una revista fundamental y no representativa.

Fundamental, porque en El Artista aparecen por primera vez varios de los elementos más característicos del cuento romántico: fragmentarismo, división del cuento en escenas, preponderancia del tema histórico, exaltación de la figura del artista, protagonista masculino sensible e impresionable y femenino débil y pasivo, amores contrariados que acaban en tragedia, gusto por los ambientes oscuros y tenebrosos...

No representativa porque los caminos que abren los cuentos que encontramos en las paginas de la revistas de Ochoa y Madrazo no van a ser seguidos por el resto de las publicaciones españolas. Una comparación de la configuración temática de los cuentos de El Artista y del promedio de los cuentos publicados entre 1835 y 1850 puede ilustrar estas diferencias. Es llamativo en El Artista la ausencia total de cuentos de temática moral, así como de los costumbristas. Hay aquí una diferencia muy clara con el Semanario Pintoresco Español que dirigió Mesonero, que, desde el principio introdujo esas dos temáticas en su revista. Tampoco aparecen cuentos de índole religiosa ni narraciones populares. Esto tiene

\footnotetext{
${ }^{3}$ B. Rodríguez Gutiérrez, «La narración breve en tres revistas románticas: <<Observatorio Pintoresco (1837), El Panorama (1838-1841), La Alhambra (1839-1843) >>, Philologia Hispalensis, XV (2001), pp. 189-208.

${ }^{4}$ Estos cuentos están reproducidos y analizados en Madrazo y Kuntz (2004).
} 
una clara explicación: el conflicto básico de los relatos de El Artista es amoroso. Un amor contrariado por las circunstancias: una pareja enfrentada a un mundo hostil o un amor no correspondido. En «Stephen» los dos enamorados, Matilde y el protagonista, se enfrentan a la oposición de la celosa madre de la joven (y a la postre madre también de Stephen): Matilde muere de la impresión cuando su madre, tras una oscura maquinación, la convence de que Stephen la ha abandonado, y Stephen, inocente de toda responsabilidad, se suicida tras la muerte de su amada. En «El Castillo del Espectro» mueren Alfonso e Irene, víctimas de la venganza del fantasma del malvado señor del castillo. Después del rescate de Irene de la prisión en que el castellano la ha encerrado, el fantasma del malvado precipita a la joven pareja al fondo de las aguas, justo en el momento en que los felices amantes iban a contraer matrimonio. En «Luisa», Arturo y Luisa se enfrentan a la enemistad del padre de ella, un Barón alemán, empeñado en una boda ventajosa para la familia desde el punto de vista económico, pero que horroriza a la sensible y enamorada joven. El padre decide asesinar a Arturo, y una vez muerto, el fantasma del novio viene a recuperar a su amada, tras de lo cual el río devuelve al enloquecido Barón los cadáveres de los dos amantes. «Beltrán» y Elmira son culpables de una amor nefando y sacrílego, que ofende a los hombres y a Dios. Son castigados con la muerte y condenación de ambos, convertidos en sombríos fantasmas que vagan por las ruinas del castillo. También condenada esta Inés Chacón («La Mujer Negra») culpable de una amor prohibido. Tras de huir de su casa y desobedecer a sus padres, de ser causa indirecta de la muerte de su padre, de manchar el honor de su apellido, ha sido abandonada por su amante y reza desconsolada por las noches en una antigua capilla. Cuando reaparece el padre, que en realidad no ha muerto, Inés cae desvanecida y muere, tras de un fuerte golpe en la cabeza, a pesar del perdón de su padre. Amor contrariado también el de Jenaro y Ángela, dos inocentes a los que la sociedad y la religión reprueban por un crimen, el incesto, que ellos son inconscientes de cometer. Su condición de hermanos ignorados es la causa de las acciones de «Yago Yasch», que causa la ruina, la infelicidad, y la muerte de los dos, sólo para impedir que Jenaro caiga en el incesto inconsciente. Y eso lo hace por «cariño». Amor imposible el de «Abdhul-Adhel, el Mantés», muerto por orden del inquisidor Meneses, el tío de su amada y padre ignorado del propio Abdhul. Muerte, la de Abdhul, que origina también el suicidio de su amada, el asesinato de su ignorado padre y el suicido también de la ejecutora del inquisidor, la propia madre de Abdhul. Amor truncado por la muerte también el de Zelma y «Ramiro», que tras de separaciones y desgracias, cuando al fin se encuentran reunidos, pierden su esperanza de felicidad por obra de Reduán, el padre de Zelma, que mata a Ramiro en venganza por la muerte del caudillo Almanzor. Muerte también de los dos amantes de «El Torrente de Blanca», Blanca y Enrique, víctimas de los insensatos y criminales celos de Alfonso, que prefiere suicidarse y causar al tiempo la muerte de los tres, antes de consentir en la felicidad de su rival y de su amada. Muerte igualmente de la amante del joven Carlos V en «1534», de forma oscura, escondida y dejando sospechas de asesinato, poniendo fin a un amor prohibido. La muerte ha roto los amores de dos personajes que se lamentan: «Alberto Regadon», que a lo largo de su travesía por el crimen y la desesperación recuerda con amargura a su dulce Catalina, única y perdida luz de su existencia y «Arindal» que llora su dolor y se suicida ante la tumba de Daura. Amor no correspondido en «Zenobia» que, en aras de su fervor patriótico, abandona a Enrique, su enamorado, entregando su vida a su amada patria, Polonia. Fracasado en «Pamplona y Elizondo», cuando Eduardo no encuentra en Isabel el alma gemela que esperaba y que necesitaba y cae en un desinterés por la vida 
que hace que no se recupere de los sufrimientos causados por la batalla y la cautividad, y le lleva a la muerte y en «Alucinación!!!» en el que el narrador descubre que la mujer que le mira con insistencia en la iglesia y que el ha adornado de las mejores galas del amor en su fantasía, es ciega.

Este conflicto básico de las relatos de El Artista no tiene cabida en cuentos costumbristas, morales y populares. Se realiza, pues, a través de narraciones históricas, cuentos fantásticos y relatos amorosos de época contemporánea.

El conflicto, como ya hemos visto, acaba en la gran mayoría de los casos con la muerte. En catorce relatos de los quince que hemos mencionado antes mueren los dos amantes o uno de los dos. Hay un tono trágico definido y persistente que toca a casi todos los cuentos.

Hay un gusto muy perceptible por pintar ambientes tétricos y oscuros, por las escenas nocturnas y por los escenarios misteriosos, aunque no haya fantasía en el relato.

Esta preocupación por el conflicto amoroso tiene unas claras connotaciones del romanticismo más innovador y revolucionario. Como indica Shaw $(1997 ; 317)$, hablando del teatro romántico, el drama genuinamente romántico es el que incorpora la injusticia cósmica del mundo «a través del tema del amor contrariado por el destino, que acaba en sufrimiento y muerte. Tema fundamental del romanticismo subversivo, opuesto al amor amenazado por las circunstancias pero preservado por la firmeza y la fe religiosa, el paradigma del romanticismo histórico.» Esa locura, esa revelación del amor romántico es la que mueve a los personajes de los cuentos de El Artista: la que hace a Beltrán perder su vida y su alma por su amor, a Matilde morir del dolor del abandono y a Stephen suicidarse ante ella, a Alberto Regadon entrar en un viaje infernal, privado de toda esperanza por la ausencia de su amada, a Arindal a suicidarse ante la tumba de Daura. Esa es la locura que ya no va a aparecer en otras revistas. Locura, pasión, arrebato amoroso que es sustituido por el amor morigerado, tranquilo, disciplinado y respetuoso con la religión, la sociedad y los padres que encontramos en tantos y tantos cuentos del romanticismo conservador.

Una vez más: se trata El Artista de una publicación fundamental para la historia del cuento romántico, pero que no es, en absoluto, representativa de la generalidad de esos relatos. La opinión de Rafael Lozano Miralles de que la revista se la «puede colocar en una posición privilegiada para el estudio de las formas y géneros que produjo el romanticismo español» no se sostiene cuando comparamos las características de sus relatos con los de la generalidad del movimiento. Mas bien, El Artista indica un camino que en gran parte no llegó a recorrerse y su fracaso frente al éxito del Semanario Pintoresco Español representa el fracaso de una modalidad romántica y el triunfo de la otra.

\subsection{Semanario Pintoresco Español}

De entre los centenares de títulos de prensa que aparecieron durante esos años, es indudable que una de las revistas de más éxito popular y literario fue el Semanario Pintoresco Español, revista fundada en 1836 por razón de Mesonero Romanos, y que, en manos de diversos directores prolongó su vida hasta $1857^{5}$.

\footnotetext{
${ }^{5}$ Un completo y detallado estudio de esta revista en Rubio Cremades (1995).
} 
Durante esos 21 años, años cruciales para el desarrollo del Romanticismo hispano, el Semanario publicó cuentos con profusión y se convirtió en una fuente privilegiada para observar la evolución de la narración breve española.

Se publicaron en la revista 228 relatos. un amplísimo número de colaboradores entre los que no hay ninguna presencia dominadora. Los dos autores con más colaboraciones son Fernán Caballero con 19 cuentos, pero todos aparecidos en los últimos ocho años de la revista y Clemente Díaz que hasta 1841, es decir, en los primeros cinco años de la revista., publica 16 relatos.

El Semanario fue una revista abierta a la mayoría de los autores y tendencias de la época. En sus páginas encontramos a nombres de la emigración (Trueba y Cossío), de los que aparecieron en Cartas Españolas (Serafín Estébanez Calderón), los creadores de revistas rivales como El Artista (Eugenio de Ochoa y Pedro de Madrazo) y No me olvides (Jacinto de Salas y Quiroga), nombres fundamentales del Romanticismo (Gil y Carrasco, Hartzenbusch), figuras más secundarias (Antonio Gil y Zárate, Gertrudis Gómez de Avellaneda., Francisco Navarro Villoslada, Mariano Roca de Togores) y autores que publicarían la mayor parte de su obra en la segunda mitad del siglo (Fernán Caballero, Eulogio Florentino Sanz). Incluso están presentes figuras tan «atípicas» del relato breve como José Somoza.

Al contrario que El Artista, el Semanario Pintoresco constituye una adecuada representación de los cuentos españoles desde 1835 a 1850. Podemos afirmar que si nuestra única fuente para el estudio del relato breve fuera la revista que lanzó en 1836 Mesonero Romanos con un éxito inesperado para la época, la conclusiones generales no variarían mucho.

Se aprecia en el Semanario, con respecto al promedio de la época una mayor aparición de cuentos costumbristas (debido sobre todo al interés de Mesonero Romanos en su época de director) y de populares (gracias a la labor de Fernán Caballero, sobre todo, y de Juan de Ariza). Por el contrario aparece una menor presencia de cuentos amorosos, relatos que en las revistas más tardías como El Siglo Pintoresco o El Laberinto van adquiriendo más importancia.

La dirección de Mesonero Romanos durante los primeros años de vida de la revista imprimió el carácter de ésta. Lo demás directores, con mayor o menor fortuna prosiguieron su estela y poco innovaron en la exitosa concepción que había conseguido multitud de lectores bajo la dirección de El Curioso Parlante.

Sólo se puede anotar como variación en la tendencia general de la revista, la diferencia entre los relatos históricos en la época de Mesonero y en épocas posteriores, pero esto es más bien producto de las tendencias del gusto que de las preferencias individuales de los directores. El tema histórico que alcanza un enorme éxito y domina en las páginas de las revistas de los años treinta con un 51,61\% de los relatos en el Observatorio Pintoresco (1837), un 58,97\% en La Alhambra (1839-1843) y hasta un $61,90 \%$ en El Panorama $(1838-1841)^{6}$, va perdiendo fuelle en las revistas que se desarrollan en la década de los cuarenta como El Siglo Pintoresco (1845-1848) que tiene un 38,46\%, El Laberinto (1843-

\footnotetext{
${ }^{6}$ Vease B. Rodríguez Gutiérrez (2001).
} 
1845), que disminuye hasta un 33,33\% y la Revista Literaria del Español (1845-1846), en la que los cuentos de temática histórica caen hasta un 8,33\%. La época de Mesonero corresponde casi exactamente con los años de las tres primeras revistas citadas y como en ellas la temática histórica es preponderante (aunque no en tanta cantidad). De la misma manera, en los años de vida del Semanario durante la segunda mitad de los cuarenta y los cincuenta, el tema histórico se va desvaneciendo y cede su lugar de preferencia al humorístico y al amoroso como ocurre en la Revista Literaria del Español (humorístico $33,33 \%$ y de amor $16,67 \%)$.

Setenta y cuatro relatos aparecieron hasta 1842 , la primera época del Semanario, con notables oscilaciones entre los años pues vemos que pasan de los cinco relatos que se publican en 1838 a los veintidós de 1840. Los autores que más colaboran con la dirección de Mesonero Romanos son Clemente Díaz con dieciséis relatos, Vicente de la Fuente con siete cuentos y José María de Andueza con seis. Autores que, con la sola excepción de un relato de Vicente de la Fuente en el primer número de 1843: «Las Colaciones», (lo que indica, probablemente, que el cuento era una herencia de la dirección de Mesonero) sólo publicaron en el Semanario como Mesonero como director.

Mesonero era un director sin prejuicios que lo mismo incluía en sus relatos cuentos románticos como «El Lago de Carucedo» ${ }^{7}$ (Enrique Gil y Carrasco, 1840) y «La Peña de los Enamorados» (Mariano Roca de Togores, 1836), que crudas sátiras antirománticas como «Rasgo Romántico» y «El Matrimonio Masculino» (Ambos cuentos de Clemente Díaz, 1836). No obstante su elección de temas indica una cierta preferencia por evitar las exageraciones y los atrevimientos románticos más exaltados. El conflicto básico ya no es aquí el amoroso trágico que era el predominante en la otra revista emblemática del Romanticismo: El Artista. De los 74 relatos que publicó el Semanario desde 1836 a 1842 apenas hay unos veinte en que la idea central sea el enfrentamiento de una pareja de enamorados con las dificultades que se oponen a su amor. Y de esos veinte tan solo en la mitad encontramos un desenlace trágico.

Para más señas, la tragedia final no es obra de un destino injusto en la mayoría de las casos, sino de factores más imputables a un individuo aislado, no a la sociedad y que raramente cuestionan dogmas establecidos (Siempre salvando la significativa excepción de «El Lago de Carucedo»).

En otros relatos el punto de vista sobre la historia amorosa cambia. Se renuevan conceptos como el honor, moralidad y respeto a la familia y al matrimonio a los que hay que subordinar y someter la relación amorosa. La pasión cambia de consideración y de valoración: pasa de ser una motivación vital que justifica todos y cada uno de los actos del enamorado a convertirse en un sentimiento pecaminoso e impuro que es preciso frenar o castigar.

En estos años de Mesonero además encontramos cuentos humorísticos con un frecuente tono antiromántico, cuentos de amor ambientados en época contemporánea, cuentos de aventuras, que son la traslación a escenarios actuales de la temática de la pareja de enamorados que con tanta frecuencia parecía en la temática histórica, y cuentos morales.

\footnotetext{
${ }^{7}$ Para un análisis de este relato, B. Rodríguez Gutiérrez (2000).
} 
Mesonero tiene claro que hay que huir de las extravagancias y las estridencias románticas y desde el primer momento procura que no aparezcan en su revista este tipo de manifestaciones.

Amor sereno y refrenado, fondo moral, negativa a la tragedia, contemplación bienhumorada de la vida contemporánea, realismo, fantasía morigerada de tradición cristiana y fondo moral: cualidades todas estas de las cuales Mesoneros gustaba y que se manifiestan en los cuentos que aparecieron en su revista mientras él era director y que iban a perpetuarse en revistas posteriores.

\section{EL LABERINTO}

El Laberinto, periódico universal. Se publicó quincenalmente desde el 1 de noviembre de 1843 al 20 de octubre de 1845. Editor-Propietario e Impresor: Ignacio Boix. Fueron sus directores Antonio Flores, desde su inicio hasta el 1 de mayo de 1845; desde entonces y hasta el final de la publicación Antonio Ferrer del Río. Desde esa misma fecha se fusiona con otra revista: La Revista Literaria de El Globo. El Laberinto intentó competir directamente con el Semanario. Para ello introdujo una novedad en la presentación: unas paginas muchos más grandes de las que eran costumbre, lo que le permitió incluir grabados de gran tamaño y calidad. Por ello los artículos de viajes y de arte (sobresalen entre todos los de José Amador de los Ríos) ocuparon un gran espacio en la revista. En cuanto a la narrativa, demostró preferencia por las novelas, publicando por entregas obras de Tomás Rodríguez Rubí (El Hermano de la Mar) y Gertrudis Gómez de Avellaneda (Espatolino).

Hay en la revista cinco relatos históricos: «Historia de los Amantes de Teruel» de Juan Eugenio Hartzenbusch, «Caín y Abel» de Isidoro Gil, «El Astrólogo y la Judía» de Eduardo González Pedroso, «La Cruz de Oro» y «El Primer Amor de un Rey». Otros cinco relatos de amor de época contemporánea: «Donde las dan las toman» de Manuel Juan Diana, «Una Madre Holandesa» de Jacinto de Salas y Quiroga, «Don Liborio de Cepeda» de Antonio Flores, «Unas Hojas Marchitas» de Baldomero Menéndez y «A un Pícaro, otro Mayor» de Luis Olona. Un relato de aventuras, «¡Ni la Trinidad te Salva!» de Manuel María de Santa Ana y uno humorístico: «Un Recuerdo de Aranjuez» de Miguel Agustín Príncipe (El cuento de Santa Ana fue vuelto a publicar en el Álbum del Bardo, en 1850)

El Laberinto, busca relatos de un nivel de un cierto nivel de calidad, generalmente largos y publicados a lo largo de varios números. Esto nos da como resultado un grupo de cuentos de estructura más compleja de lo habitual, personajes más desarrollados y dibujados que otros y más acabados que la mayoría. El nivel de exigencia debía ser alto pues no repitió ningún autor de cuentos en las páginas de El Laberinto.

Las tramas generalmente son complicadas y los personajes están claramente diferenciados entre los positivos y los negativos. Hay una evidente intención moral en casi todos los cuentos, bien por el triunfo del personaje que representa los virtudes de la moral, bien por el castigo final de quienes se apartan de ella.

Castigo final encontramos, por ejemplo, en «El Astrólogo y la Judía». Un guerrero cristiano, después de quedar manco en la guerra, es curado por un judío y se enamora de su hija. Después de aprender del judío la astrología, Alvar, el cristiano, se fuga con la joven Sahara y vuelve a su pueblo natal. Allí permanecen felices hasta que Alvar ve en los cielos que se van a separar. Lo cuenta a Sahara y esta se pregunta si no habrá forma de impedirlo. 
El diablo se les aparece y les ofrece un don: que cada uno de ellos posea el destino del otro para poder desviar los golpes que les de la vida. Aceptan y poco a poco el saber que la vida de cada uno depende del otro les hace separarse. Un criado negro que tienen, el diablo disfrazado, va haciendo crecer con sus insinuaciones la desconfianza entre ambos. Finalmente Sahara huye y al final cada uno de los amantes, enfrentado a la muerte, causa la muerte del otro. El abandono de la religión cristiana y el entregarse a la artes diabólicas es castigado por el destino: un amor maldito no puede sobrevivir.

Castigo también, pero esta vez por el crimen, nos encontramos en «Caín y Abel». Camilo, un joven veneciano, esta a punto de verse detenido por la justicia. Olivia, su amante, que le ha inducido a cada vez mas crímenes, urde uno nuevo para salvarle. Aprovechándose de su increíble parecido con el Conde de Laval, un joven francés, le asesina para que Camilo ocupe su lugar. Al final el crimen y la sustitución son descubiertas y se revela que Camilo y el Conde de Laval son hermanos. Camilo muere ejecutado y su amante de desesperación.

También hacia el castigo final se dirige la historia de «¡Ni la Trinidad te salva!». Un antiguo bandolero de la partida de José María el Tempranillo cuenta una historia en una venta de camino sobre una joven a la que secuestró y violó. Entre los huéspedes de la venta está la propia joven, semienloquecida, y el padre de ella, un aristócrata, que hace tiempo que ignora el paradero de su hija. Al comprender la situación mata el padre al bandido y recobra a su hija.

Un castigo final encuentran también los enemigos de la pareja protagonista en «A un Pícaro, otro Mayor». Durante la primera guerra Carlista, Isabel, esposa de un conde legitimista esconde a un antiguo novio suyo, carlista. Su criado Mauricio, un personaje satánico, maquina un plan para asesinar al conde, hacer aparecer como culpables a lsabel y a Enrique, el carlista y de esta manera quedarse con la fortuna del conde. Lo consigue con ayuda de Jaime y Felipe dos bandidos como él y huyen todos a Lisboa donde tienen secuestrada a Isabel. Al cabo de dos años regresa Enrique con otro nombre (no se explica de que manera lo ha conseguido pues había sido apresado) y consigue fugarse con la Condesa, mientras que Mauricio, Felipe y Jaime se matan entre ellos.

Una clara intención moralizante se puede encontrar en «El Primer Amor de un Rey». El joven Carlos I, en un paseo corteja a Doña Flor. Les sorprende el Conde, padre de ella, y le recuerda al rey sus obligaciones de monarca. El Rey le da la razón al Conde y se va de la casa de éste. El Rey es aquí, un ejemplo de cortesía, moderación, respeto a los mayores y sentimiento religioso. También de intención moral, en este caso de la sabiduría de los padres para controlar los absurdos enamoramientos de los hijos es «Don Liborio de Cepeda». La hija de Don Liborio entabla una relación con la que no está de acuerdo su padre que quiere casarla con un personaje que su hija detesta. Al final el amante abandona a la hija y se suicida por estar sin dinero y la hija, una vez recuperada, se casa con un comerciante gordo de Castilla, con quien es completamente feliz.

Como en todas las revistas en las que domina el romanticismo conservador, no podía faltar el toque crítico a los estereotipos románticos. «Un Recuerdo de Aranjuez» se burla de un joven, perfecta representación del romántico aficionado a los viajes, que sufre mil desventuras, y que de vuelta a Madrid, renuncia a sus afanes de ver mundo. «Un Recuerdo de Aranjuez» es uno de los mejores relatos de esta tendencia en el que, para variar, no falta 
el elemento satírico antiromántico. Es un cuento centrado en las desventuras de un viajero de esta especie. El protagonista es un perfecto viajero romántico, que decide de pronto viajar por pura necesidad del espíritu:

Pues señor...yo me siento inspirado, yo necesito un sitio a propósito para cantar. ¿Dónde me dirigiré? La atmósfera de la corte me ahoga y es preciso salir de Madrid. ¿Qué pensamientos podrían ocurrírseme en la muy conocida villa, que no se resintieran de la confusión y el caos que reina en ella? A otra parte, poeta, a otro sitio. La primavera ha desplegado sus galas; el bellísimo mes de mayo te brinda con sus flores: tu inspiración y tu genio se desarrollan en el campo. Vamos al campo pues, vamos a cualquier parte, con tal que [...] en una palabra que pierdas de vista a Madrid.

Así resuelto sale el viajero y coge un billete en la diligencia de Aranjuez, que es el primer viaje que encuentra. Renegando contra un país donde no hay caminos de hierro se dirige a la villa. Cuando llega allí se da cuenta de que con las prisas se ha olvidado dinero y pasaporte y que no tiene suficiente para una habitación para la noche y luego comprar el billete de vuelta. Obligado a dormir en Aranjuez, pues ya no hay diligencias, pasa la primera noche en el palco de un teatro donde se ha quedado encerrado, la mañana siguiente es detenido como sospechoso de haber robado un reloj, después de aclarar el equívoco se mofa de él un pilluelo que le roba el poco dinero que le queda y su propio reloj, haciéndole extraviarse en el laberinto de los jardines del Príncipe, donde debe pasar la segunda noche. Finalmente decide escapar de Aranjuez antes de que le ocurra algo peor y vuelve a Madrid andando, recordando tristemente sus quejas iniciales sobre la falta de caminos de hierro.

En «Unas Hojas Marchitas» se da una curiosa contradicción: un desarrollo de la historia que enfrenta a las dos formas de entender la vida: el protagonista, delicado, romántico y, en el fondo, pasivo e inútil, y el personaje a quien cuenta la historia, absolutamente positivista y antiromántico. Enrique, un joven militar, conoce a Laura cuando está asediada en la playa por un hombre que la pretende violar. Se enamoran pero la madre de ella la obliga a casarse con otro pretendiente y Enrique no se atreve a declararse. El día de su boda Laura invita a Enrique a que venga a su casa y allí le cuenta que su marido es el fustrado violador y que ella ha tomado veneno para suicidarse.

El relato comienza con el encuentro del narrador de la historia con Enrique, un amigo al que hace años que no veía. Enrique está triste y taciturno y su único consuelo es besar una cajita que lleva en el pecho y que contiene unas secas hojas de rosa. Ante las preguntas del narrador le da un manuscrito en donde cuenta su historia. En el manuscrito, Enrique insiste en su amor de adoración, de reverencia.

¡Cada vez se me figuraba más hermosa! Mi pasión se aumenta prodigiosamente, y ella, quizás sin saberlo, daba pábulo a lo que llamaba entonces amistad...ipero no lo era, no!. Llegué a quererla con delirio y sólo a su lado encontraba mi corazón sosiego. Al llegar a su domicilio palpitaba agobiado de temor y esperanza y si por desgracia había salido solo su vuelta era capaz de consolarme. Jamás sin embargo pude decirla: ¡te amo!. Me inspiraba su vista un respeto inconcebible y nunca rozaron mis manos tocar ligeramente aquellos vestidos cuyo roce me electrizaba

La narración sigue y la amada de Enrique le revela que su madre la va a obligar a casarse con otro hombre. Enrique queda anonadado, pero no se atreve, a pesar de la 
situación, a declarar su amor y sigue manifestándose como un adorador pasivo, interpretando gestos, lleno de dudas y sin decidirse a plantear su amor.

La mirada de amor quema como la lava de un volcán. El ojo cuando la dirige está enjuto; la vista fija y penetrante, sólo busca la pupila del ojo que adora. En hallándola se para como quien nada más desea, la mira con lánguida tristeza y en viendo que su mudo lenguaje es comprendido, se aparta satisfecha con una dulce sonrisa y se fija en el suelo como si estuviera cansada. El corazón late con celeridad, el pecho, antes oprimido, respira con violencia, exhalando profundos suspiros y a veces se llora sin poderlo remediar.

La suya no era así... no. Era una mirada tierna, cariñosa y llena, si se quiere, de fuego y de expresión, sí. Pero una mirada tan sólo de gratitud y amistad. ¡Yo la quería con delirio!

Al ser incapaz de declararse le canta una canción por el compuesta titulada «El Triste», en la que le declara poéticamente su amor. Prosigue la historia con su dramático final del suicidio de la protagonista, la desesperación de Enrique y la huida del marido. Es muy representativa del gusto de los autores románticos por la teatralización del relato la escena de la muerte de la protagonista, en un monólogo casi «operístico». Los signos de admiración y los puntos suspensivos son utilizados con profusión por el autor para acentuar el dramatismo de la situación.

-Aparta!... aparta! -repuso ella deteniéndole [a su esposo].- ¡Tus ojos me horrorizan!... no me toques... no... ¡aún se resiente mi seno de tu primer beso impuro! ¡Cruel, no profanes los últimos momentos de mi vida!... Si la iglesia pudo darte algún derecho sobre mí, jamás fue autorizado por mi corazón... ¡Cada vez te aborrezco más, hombre infame! ¡Huye lejos de mí! Y tú, Enrique, que fuiste una vez mi ángel tutelar, vela en este momento por mi virtud. No permitas que manos profanas me toquen [...] ¡A Acércate y no temas!... ¡Ah!... ¿Tú también palideces?... ¿No me respondes?... ¿No me amas, quizás?... pero sí... sí... tus ojos me lo han manifestado una y mil veces ¡yo también te amo!... Ven, ven... aparta de mí este monstruo... que muera yo pura... ipura como la ilusión de un niño!

Después de terminar, hay este curioso epílogo, en el que el narrador se burla de los sentimientos de Enrique y rechaza su visión romántica de la vida, visión romántica que, según el, es causante de la desgracia de la historia.

Hasta aquí el manuscrito de mi amigo.

Pasados algunos días volvió Enrique a visitarme y se lo entregué.

-¿Lo has leído?-, me dijo al tomarlo

-Seguramente.

-¿Y qué tal?

-No te compadezco ni más ni menos.

-¡Cómo!

-Como lo oyes.

-Pues te aseguro que no lo esperaba.

-Tampoco esperaba yo hallar en ti un enamorado tan cobarde. Si padeces, si la pobre niña tuvo un fin tan desastroso, tuya y de nadie más es la culpa.

-¡Mía!

-A no dudarlo. Yo en tu lugar...

-¿Qué hicieras?

- ¡Toma! Haberle declarado mi amor, lisa y llanamente, como Dios manda. 
- ¿Y su recibía un desengaño?... ¿Si ofendido su amor propio, te despedía de su presencia, quitándote hasta la esperanza?

-No lo haría.

$-¿$ Y si lo hiciera?

-Santas pascuas.

- ¡Se conoce que no has amado en tu vida!

-¡Cómo que no! Más de cien novias he tenido, a cual más hermosa. Pero yo no ando en chiquitas, ni me rompo la cabeza escribiéndolas canciones que producen por lo general muy mal efecto.

Los comentarios del narrador desmontan la visión romántica y doliente que da Enrique de la historia y la presentan con un aspecto distinto. El romanticismo vuelve a perfilarse como una opción negativa.

\section{REVISTA LITERARIA DE EL ESPAÑOL}

Revista literaria de El Español, periódico semanal de literatura, bellas artes y variedades. Se publica desde el 1 de Junio de 1845, los domingos, por la empresa del diario El Español. Hasta el número 44 (30 de Marzo de 1846) forma el tomo I, en el que no consta nombre del director. En el número 45 comienza el tomo II. A partir de aquí comienza el Tomo II. Cambia el sistema de numeración y aparece como director Francisco Navarro Villoslada. Dura hasta el 27 de julio de 1846.

Sigue la tónica tradicionalista y conservadora que todas las revistas tomaron desde que desapareciera El Pensamiento. Domina ampliamente el cuento humorístico con siete relatos: «Mis Viajes. Bosquejo de un cuento» de Gabino Tejado; «La Atanasia»y «Los Tres Locos» de Ildefonso Ovejas; «Aventuras de un Filármónico» de Francisco Navarro Villoslada; «Aventuras de un aficionado a los puntos de vista» de R.M.; «No y Sí. Sí, pues Sí»; y «Dos Páginas de las Memorias de un Sordo». Además dos cuentos morales: «El Robado y el Ladrón» de Gomez Colón y «Una Conversión»; dos de aventuras. «Historia de uno de los Niños de Ecija» y «Una Acuarela» de Lino Talavera; un cuento de amor («El Amor de una Fea» de Luis de Montes) y un relato histórico («No hay plazo que no se cumpla, ni deuda que no se pague» de Francisco Lumbreras).

Como en otras revistas de estos años el tono moral está muy presente en los relatos. En «El Robado y el Ladrón» encontramos un mensaje moral muy evidente. Durante la guerra civil (1836) un marino veterano arruinado no tiene más remedio que recurrir al robo para alimentar a su mujer y a sus tres hijos. Inadvertidamente roba en la casa de un oficial de marina, antiguo superior suyo. El oficial se da cuento del robo, descubre al ladrón, le sigue hasta su casa y al ver las condiciones de vida de él y de su familia, queda conmovido y le perdona. Pero a los pocos meses el marino muere víctima de la vergüenza.

El mensaje moral está también presente en un cuento histórico como «No hay plazo que no se cumpla ni deuda que no se pague». Comienza el cuento con la presentación de tres personajes en una iglesia en Madrid en 1611: un caballero vestido de negro y con anteojos, una joven que acude a confesarse y un galán emperifollado que la persigue. Después se cuenta la historia (anterior en el tiempo) de la seducción de Doña Ana de Benavides por Don Lope de Figueroa, como es descubierto por la familia de ésta y como don Lope mata al padre y al hermano de Ana. En su agonía el padre le emplaza a rendir cuentas a Dios en el plazo de un año. Vuelve el cuento a la escena inicial: el galán molesta a la mujer en la iglesia y el hombre de negro se lo recrimina. Se entabla un duelo y muere el galán que era 
don Lope mientras que su matador era Francisco de Quevedo. El castigo final al malvado es muy del gusto de los cuentos de entonces, fuesen directamente morales o no.

También hay cuentos humorísticos con fondo moral. Es el caso de «Aventuras de un Filarmónico», en que se ridiculiza la manía musical de un joven romántico y se alerta contra los peligros de la vida en la corte. También una figura romántica ridiculizada es el protagonista de "Aventuras de un Aficionado a Puntos de Vista», al que su obsesión de contemplar todo tipo de paisajes desde lugares elevados le causa mil problemas. En uno y otro caso ambos románticos curan de sus manías, viendo el ridículo en que les hacen caer. Otro relato humorístico de fondo moral es «Dos Páginas de las Memorias de un Sordo» en el que el protagonista se finge sordo y así consigue el aprecio de la gente, el éxito en la vida y el amor y el respeto de su mujer.

Merece la pena el cuento «La Atanasia», un buena parodia de Atala debida a la pluma de Ildefonso Ovejas, admirador, amigo y primer estudioso de la obra de Ros de Olano. Ovejas es también autor de «Los Tres Locos» relato en el que la huella de Ros de Olano es muy perceptible. Tres locos escapan de un manicomio en Zaragoza y se extravían en la sierra hasta que encuentran un castillo fantástico donde el rey del mundo oye sus historias: uno se cree calabaza, otro tiene los ojos en el estómago y otro ha encontrado la cabeza de bronce que menciona El Quijote y se la ha colocado en lugar de la suya. Al final salen del palacio pero no consiguen llegar a Barahona, el pueblo hacia donde se dirigen, por una extraño conjuro del diablo.

El suelo estaba nevado; a poco rato apareció Baraona en el horizonte y los viajero seguían andando, y a cosa de media hora volvió a aparecer Baraona hacia el mismo punto, y los coches seguían andando y cada vez andaban más deprisa; al cabo de otra media hora corta apareció otra vez Baraona y los coches a andar y más andar y los caballos parecían espoleados por jinetes invisibles; trotaban, galopaban, escapaban, y volvía a aparecer Barahona en el horizonte y así pasaron una hora y otra hora.

$\mathrm{Al}$ cabo de este tiempo se vio moverse en el llano un punto negro que minuto por minuto iba creciendo, y extendiéndose y alargándose sobre todo, y los coches corrían y corrían y de vez en cuando Baraona aparecía y volvía a desaparecer. Ya por fin aquel punto negro se agrandó tanto que parecía una procesión, y no era efectivamente otra cosa: los habitantes de Baraona habían distinguido desde su casa unos bultos que a cosa de media legua daban vueltas y más vueltas, girando sobre sus mismas huellas en círculo continuo, corriendo, volando. Por todo lo cual no dudaban que fueran las brujas y salían a acometerlas. Delante venía el corregidor con su vara, y detrás dos hileras de osos con capas y sombreros, como si fuesen hombres y a la cola una infinidad de ratas con mantillas en tropel, lo mismo que van las mujeres detrás de las procesiones.

Esta singular procesión, que sin duda se entretenía el diablo en desfigurarla bajo aquella forma se encaminó derecho hacia los bultos del llano que corrían más y más, siempre en círculo. Detrás del corregidor venía el diablo y cuando la procesión llegó cerca de los carruajes de los locos, el diablo comenzó a soplar, a soplar y con aquel soplo el corregidor, perdió con la vara tierra y dio a volar y los que seguían, viendo esto, le agarraron de los faldones y el se los llevó y volaron también y tras de estos, agarrados unos a otros fueron volando todos; y el diablo soplar y más soplar y los coches ya no corrían, volaban y el corregidor detrás, arreándoles a varazos, y con él toda la procesión volaba detrás, todos en círculo sin salir nunca, y aquello ya no era correr, ya no era volar, era un huracán indomable, 
era un vértigo, era una confusión. Poco a poco los coches y la procesión se iban haciendo invisibles, tan de prisa pasaban como relámpagos, como rayos, y ya no se les veía ni se les oía, sino que seguían siempre, rápidos como el pensamiento, sin salir del círculo vicioso, y todavía están y estarán así por los siglos de los siglos, si Dios no pone remedio en ello.

La combinación de fantasía desbordada y la intención humorística que se concreta en imágenes grotescas y absurdas. Eso es lo que Ovejas toma de Ros de Olano Pero si en Ros esa combinación lleva a veces a argumentos que se abandonan sin terminar debido al grado de complicación de la historia, esa imposibilidad de lograr un final de la narración se ve aún más claro en este cuento de Ovejas.

«La Atanasia» por su propia naturaleza de parodia está más ordenada y estructurada. Un anciano de Vallecas cuenta su viaje a Murcia donde fue robado, queda encadenado a una bella mujer desnuda a la que odia desde el primer momento y cuando ésta muere queda vacío sin nadie a quien odiar. Todo el cuento está escrito con un estilo ampuloso, presentando el viaje de Madrid a Murcia como selvas y bosques, adoptando el narrador protagonista un tono de indio literario, hablando continuamente de los jefes y de los ancianos, etc. El narrador pide al anciano de Vallecas que le cuente su historia «con el lenguaje que uso Chateaubriend». El diálogo de odio de los protagonistas es una referencia cómica al estilo del escritor francés. -Mujer,-exclamé con frenesí-, yo te odio mortalmente, te odio más que el día a la noche, más
que el lobo rabioso al agua. Maldita seas.
-Maldito seas tú, malvado que me tienes sujeta y no me dejas andar. Muérete cantaré de alegría.
¡¡Oh, mujer! ¡Cómo me deleito en aborrecerte! No sabes tú lo que es esta pasión, este frenesí que se apodera del alma y la consume. ¡Oh, aborréceme, aborréceme, quiero que me aborrezcas, para ver si puedo odiarte más!
-¡Oh, yo te odio tanto como no odié nunca jamás! ¡Sí, yo te odio!
-¡Oh, qué placer! Me odias. ¡Qué placer!
¿Quién comprendería estas alegrías, la dulzura de estas palabras, pronunciadas en el silencio de los bosques a la luz de la luna?

Otro relato humorístico, ya sin consideraciones morales, es «No y Sí. Sí, pues Sí». En una serie de cartas, Teodoro cuenta a Luis la historia de su matrimonio. Obligado por su padre a dejar Madrid, a volver a Méntrida, su pueblo, y a casarse con una prima a la que apenas conoce, resuelve negarse a ello y en la ceremonia de la boda contesta con un «no» a la pregunta del cura. Ante el escándalo se va del pueblo y, en viaje a Madrid, para en Navalcarnero. Allí le encuentra la frustrada novia (que hasta el momento parecía inocente y tímida) y con una energía que sorprende a Teodoro le conmina, amenazándole con una pistola, a reparar la humillación que ha sufrido repitiendo la ceremonia y siendo ella la que dijera «no» esa vez, para que quedara claro que ella no era un novia abandonada, o de lo contrario le mataría allí mismo. Teodoro accede y cuando se celebra la ceremonia la novia dice «sí» y Teodoro se encuentra, como dice la firma de la última carta, marido por fuerza. Las cartas están escritas en las fechas inmediatas a los acontecimientos que se cuentan, de manera que Teodoro no sabe hasta el último momento las consecuencias del engaño que está preparando su prima. 
Una especial mención merece el relato de Lino Talavera ${ }^{8}$, «Una Acuarela». «Una Acuarela» fue publicada después de la muerte del autor según indica una nota que hay al final del relato, pero no se nos dice cuando ocurrió su muerte. Los otros cuentos que conocemos de Talavera («Policarpa», «La Paloma del Diluvio», «La Muerte de un Ángel») aparecieron todos publicados en 1841. Es último relato es sin duda el mejor del autor venezolano. El protagonista cuenta una historia que le ha recordado la contemplación de un cuadro. Alférez en un barco de guerra venezolano, ve como el barco, capitaneado por un mestizo, el teniente Romualdo, abandona la armada y se dedica a la piratería sin que el protagonista, joven de apenas diecisiete años, pueda hacer nada para impedirlo. En una de las incursiones Romualdo secuestra a una mujer y el protagonista decide protegerla y más cuando se entera que es la prometida de un oficial amigo suyo Al final consigue liberarla, aunque para ello tiene que renunciar a denunciar las piraterías de Romualdo. El cuento destaca por renunciar a acontecimientos sorprendentes e inverosímiles para desarrollar la acción y atenerse a una historia lógica y plausible, por la caracterización de los personajes, mucho mejor conseguida que en otros relatos de este estilo y por la importancia que se concede a la figura de Romualdo, el malvado de la historia que se va engrandeciendo conforme ésta avanza y al que el protagonista recuerda con indisimulada admiración, como se puede ver en el momento en el que el barco embarranca en unos arrecifes, durante una incursión pirata de Romualdo en tierra.

Yo tenía un secreta confianza en el teniente Romualdo; él era valiente, superior a todos los peligros. Y los desesperados lances en que se había encontrado se me representaban a la imaginación en aquel instante para darme la esperanza de que él volvería a la balandra y que con su atrevido genio nos sacaría de tan dura situación. Ninguna confianza tenía yo en su compasión, porque sabía que era capaz de arrojar con sus propias manos al mar al que por un momento creyera causa del naufragio, pero la opinión que tenía yo de su carácter me aseguraba que vendría primero a donde su deber lo llamaba y moriría primero que abandonar su buque como un cobarde.

[...] ¡Cuál sería su indignación al subir a bordo y conocer el verdadero estado del barco! Sin embargo ni la muestra más ligera de terror ni de duda se notó en su rostro; en el momento empuñó la bandera y mandó formar sobre cubierta; luego, llamando al piloto y al contramaestre les ordena el reconocimiento del casco y mientras lo verificaban permaneció dando paseos de proa a popa con su mano derecha sobre la empuñadura del cuchillo que llevaba a la cinta. ¡Desgraciado del que hubiera manifestado entonces cobardía!. Habría quedado muerto en el acto bajo su formidable hierro. Su frente estaba serena pero cubierta de una sombra que revelaba lo que estaba pasando en su corazón; sus ojos parecían despedir

\footnotetext{
${ }^{8}$ La escasa información que tenemos sobre Lino Talavera nos permite decir apenas que se trata de un autor venezolano. Probablemente de Maracaibo si tenemos en cuenta la detallada y nostálgica descripción que hace de la ciudad en uno de sus cuentos. Veinticinco años tenía en 1840 según afirma en su fragmento «El Escéptico» y tal vez no llegaría a cumplir los treinta pues su último relato, «Una Acuarela» fue publicado en 1846 después de la muerte del autor según nos informa una nota del editor de la revista. En España desarrolló su vida en Granada. Allí publica toda su obra, con la excepción de su cuento póstumo, que apareció en la Revista Literaria de El Español,. Pero el cuento aparece firmado en Granada, con lo que queda claro la unión del venezolano con la ciudad de la Alhambra.
} 
rayos de fuego y la majestad y firmeza de sus pasos le asemejaban al león que reconcentra toda su rabia para arrojarse sobre la presa que busca cauteloso.

Este relato y las situaciones del cuento no dejan de recordar a una novela mucho más moderna: El Lobo de Mar de Jack London. Como en esta novela la peripecia cede el protagonismo a la presentación de un personaje, que en principio aparece como negativo (Romualdo, Larsen), y que poco a poco se va adueñando de la novela y haciéndose acreedor a la admiración del narrador. Pero Talavera acierta al elegir a un adolescente como narrador, lo que explica su involuntaria admiración por la imponente y maléfica figura de Romualdo, mientras que London, preso de sus concepciones filosóficas, se esfuerza en presentar a un esteta, crítico de poesía y hombre culto, admirado y anonadado ante la energía primaria y la superioridad de Larsen.

\section{El Siglo Pintoresco}

El Siglo Pintoresco, periódico universal, ameno e instructivo, al alcance de todas las clases. Publicación semanal, desde Abril de 1845 a Enero de 1848. Tres tomos (1845, 1846 y 1847/48). En el tomo de 1845 aparecen como directores Vicente Castelló (de la parte artística) y Francisco Navarro Villoslada y M.M. Bartolomé de la parte literaria. Imprenta de Vicente Castelló. En el tomo de 1846 el impresor es Baltasar González, y los directores Francisco Navarro Villoslada (parte literaria) y Vicente Castelló (parte artística). En el tercer tomo siguen los mismos directores hasta Agosto de 1846 fecha en la que se hace cargo de la dirección Angel Fernández de los Ríos sin que se diferencie entre parte artística y literaria. En esta misma fecha se unen las empresas de El Siglo y de El Semanario Pintoresco.

El Siglo Pintoresco muestra claramente la tendencia a la que van derivando las revistas al final de la cincuentena: de las trece narraciones seis son históricas y siete de amor de época de tema contemporáneo. Las históricas son «Bernardo del Carpio», «La Reina Egilona», «El Ahorcado de Palo» de Gabino Tejado, «El Caballero sin Nombre» de Francisco Navarro Villoslada, «La Corona de Fuego» de Benito Vicetto y «El Amor de una Mujer» de Ángel Fernández de los Ríos. Los cuentos de amor son «Un Cuento de Pescador» de M.M.B., «La Tercera Dama Duende» de José Heriberto García de Quevedo, «Secretos de Familia» de Ángel Fernández de los Ríos, «La Perla de Nápoles» de Gregorio Romero Larrañaga y tres relatos de Ramón de Navarrete: «Misterios del Corazón», «Una Mujer Misteriosa» y «Un Cuento de Hadas».

No hay grandes novedades en los cuentos históricos. Exaltación del patriotismo y de los valores cristianos en «Bernardo del Carpio» y «La Reina Egilona». Un héroe nacional y un mártir de la religión son los protagonistas. Temas y personajes clásicos ya en el cuento histórico romántico en los otros relatos. Cervantes en «El Amor de una Mujer» en que el autor desarrolla una historia más sobre el tema del destino desgraciado del artista, ahora perseguido por el odio de una mujer rechazada.. La venganza justiciera en «El Caballero sin Nombre». Un caballero se encuentra con Alfonso VI que está sitiando el castillo de Moscoso. El caballero no conoce su nombre ni su identidad. La historia va descubriendo que es sobrino del Conde Ataúlfo, dueño del castillo, e hijo del hermano mayor del Conde que está preso en palacio desde hace largos años aunque todos le creen muerto, hijo también de la esposa de Ataúlfo que se ha vuelta a casar con el Conde, al haber sido engañada por éste y creerse viuda. Consigue con el auxilio del rey, rescatar a su padre y 
vengarse de su tío. Venganza también, pero ahora de un padre sobre un malvado obispo, violador y asesino de su hija, hay en "La Corona de Fuego», cuento en el que no falta un evidente erotismo de la enfermedad. Tras una introducción que explica lo muy propias que son las tierras que hay junto al río Miño para las narraciones románticas, cuenta una leyenda de Monforte de Lemos. El Conde de Lemos tenía un hermosa hija, Elvira, que había causado el amor sacrílego e ignorado del Abad del monasterio de San Vicente del Pino. Cegado por ese amor el abad hace asesinar a un paje al que Elvira ama, y después aprovechando una ausencia del Conde viola y después envenena a Elvira. Cuando el conde llega y encuentra a su hija muerta no sospecha nada (la joven estaba muy enferma). Pero al cabo de tiempo un criado suyo que va a morir y que había sido comprado por el Abad le cuenta los crímenes de éste. El Conde prepara un gran festín y en medio de él anuncia los crímenes del Abad y le mata obligándole a ponerse una corona de hierro al rojo vivo. Es interesante ver que el autor cuenta que la iglesia ha reelaborado esta leyenda para exculpar al abad y presentar al conde como un asesino y no como un vengador.

«El Ahorcado de Palo» presenta a uno de los personajes históricos predilectos de la literatura española: Pedro el Cruel. El rey Pedro el Cruel triste por la reciente muerte de María de Padilla es atacado y despojado de un relicario de la muerta por un tal Juan el Malo que ya ha intentado matarle en tres ocasiones. En una segunda escena Juan el Bueno, un cazador y soldado de Don Pedro, se da cuenta de que su cuñado es Juan el Malo y se entera de que el rey ha puesto precio a su cabeza. Va a ver al rey e intenta hacerse pasar por Juan el Malo para poder sacar a su hermana de la pobreza., pero en ese momento aparece el auténtico Juan el Malo. Es apresado y ahorcado, pero cuando van a comprobar si está muerto encuentran que se convertido en un maniquí de palo que se quema al rociarlo con agua bendita.

Entre los relatos amorosos es interesante, para comprobar la situación de escritor profesional en la que vivían muchos de los autores, el relato «Secretos de Familia» de Ángel Fernández de los Ríos. Comenzado con ritmo lento y signos de tender a una intriga complicada, es acabado en el siguiente número de cualquier manera por la razón, reconocida expresamente por el autor, de que la publicación finalizaba y se veía obligado a culminar la narración en apenas unas horas.

He aquí querido lector el desenlace que primero se me ha ocurrido para los sucesos que había comenzado a contarte: dos ventajas tiene por lo menos, la de ser breve para ti y la de haberme ocupado poco tiempo. Si la novela no te gustaba, he hecho bien en complacer al editor que querían una conclusión en pocas líneas y escrita en breves horas; si había llegado a interesarte, acaso en otra ocasión te enteraré de los maravillosos sucesos que tenía pensado referirte. Por ahora quedan sumergidos en el fondo de mi tintero los SECRETOS DE FAMILIA.

Es significativo que, pese a este apresuramiento, Fernández de los Ríos no descuida la retribución moral a los personajes y así la pareja protagonista, encuentra en un calle de Madrid los dos cadáveres de los malvados de la historia, sin que el autor explique ni el como ni el porqué ocurrieron estas muertes.

«La Perla de Nápoles» es una narración en la que se repiten las características de otras de Gregorio Romero Larrañaga; personajes tópicos, acción embarullada y en muchas ocasiones sin terminar y finales caprichosos del autor. El cuento comienza con la presentación de unos personajes y unos ambientes misteriosos. En Tívoli el narrador 
encuentra a una bella mujer en el cementerio intentando suicidarse. La consuela y consigue convencerla para que renuncie a su propósito pero al abandonar el cementerio encuentran el cuerpo ensangrentado de Renato, el marido de Ulpiana, la frustrada suicida. Parece haber sido herido en duelo y rápidamente lo llevan a la posada donde esta alojada Ulpiana y donde también reside el narrador, Genaro. Mientras Ulpiana atiende a su marido, la atención de Genero queda prendida en un extraño que ronda la posada. Cuando el extraño se presenta ante él reconoce a un antiguo condiscípulo, Federico, que está atrozmente envejecido. Federico le abandona sin querer contar su historia, pero Genaro conoce que algo tiene que ver con Ulpiana, pues esta al verle se aterra. Al día siguiente Renato muere, Federico no vuelve a aparecer y Ulpiana abandona la posada dejando a Genaro un libro donde se cuenta su historia. Aquí el autor termina el cuento negándose a contar la historia de Ulpiana: todo queda en el misterio. La narración es lenta, con abundantes interpolaciones, descripciones y reflexiones del narrador. Hay un definido intento de crear un ambiente.

«Un Cuento de Pescador» es una narración ambientada en la isla de Jersey, sobre una rivalidad en amores y el triunfo de los enamorados, aunque luego el autor se complace en matar a los protagonistas, porque sí, sin que el fin tenga nada que ver con la historia. En la Isla de Jersey el narrador oye a un viejo pescador contar un historia de su juventud. Los amores entre Tom y Betsy, la llegada de Butler, un rival, el desprecio de Betsy a éste y el intento de Butler de asesinarles a los dos en venganza, cosa que no consigue. De todas formas Betsy muere de una enfermedad al año y Tom poco después en la guerra. La historia en sí misma termina con el fracaso del asesino, y la reunión de los dos esposos. El añadido final consigue el efecto sombrío tan deseado por muchos de estos autores a la hora de abordar historias sentimentales

«La Tercera Dama Duende» cuenta una historia de amores y enfermedad (tuberculosis). Un grupo de jóvenes forzados a refugiarse de la lluvia cuentan historias amorosas. Uno de ellos cuenta como conoció a su amada Helena en un viaje, y como ésta enferma de tuberculosis, lo mismo que el personaje que narra la historia muere a poco de conocerse. Hay un gusto por el misterio, innecesario (y mal explicado al final) y un evidente erotismo mezclado con la enfermedad. Un vago incesto (los amantes se llaman hermanos el uno al otro) y referencias a Byron. El relato está llena de imágenes que explotan el erotismo de la enfermedad y la muerte.

Volvíme bruscamente y no pude menos de estremecerme de horror al ver la mortal palidez que cubría nuestros semblantes. En aquel momento tosió la pobre niña ligeramente y yo, por uno de esos efectos contagiosos que tan a menudo se ven en las reuniones de toda especie, empecé también a toser y me llevé el pañuelo a la boca como ella lo había hecho. Su tos cesó primero que la mía y acercándose a mí me dijo con tono tan triste y cariñoso que me hizo saltar las lágrimas.

-¡Mira hermano! La muerte está cerca y no debemos hablar de amor.

Y desplegando su pañuelo me hizo ver en él varias manchas de sangre. Involuntariamente abrí el mío... estaba lleno.

A lo largo de la narración se hacen coincidir los diálogos y encuentros amorosos con la crisis de la enfermedad, en un transparente erotismo del dolor.

Un caso especial es el de los cuentos de Ramón de Navarrete. Navarrete es el creador de un tipo de cuento de amores que iba a tener una amplia descendencia en las revistas 
españolas, en ambientes elegantes, con complicaciones de celos, personajes masculinos de vida licenciosa que son llevados al buen camino por mujeres pías y honestas, ridiculización de los personajes populares y sencillos, etc. De esta temática «rosa» es un buen ejemplo «Misterios del Corazón»

Comienza el relato en uno de los escenarios preferidos de este tipo de narraciones: el café. En general, en los cuentos de Navarrete y en los que le siguen hay cuatro escenarios claves: el café donde los hombres presumen de sus amores y comentan los amores de los demás y adonde también acuden las damas que sirven de objeto a los comentarios; los dormitorios femeninos donde las mujeres se hacen confidencias y los paseos y los bailes donde los hombres y las mujeres se relacionan. En el café se nos presenta al Conde de Peñaflor, un seductor adinerado y experto, a Justo Paniagua, un propietario jerezano, ignorante y ridículo, y al Marqués de Vivarrambla, un aristócrata orgulloso y exquisito. También están la Marquesa de Vivarrambla, una inocente mujer recién llegada a Madrid de Granada y su amiga Adela que es, sin que la inocente esposa lo sepa, la amante del Marqués. A partir de estos cinco personajes la historia se desarrolla: enterada la Marquesa de la infidelidad de su esposa decide darle celos y comienza a dejarse galantear por el Conde de Peñaflor. Éste, creyendo hacer una conquista, acompaña a todas partes a la Marquesa y el Marqués descubre de repente lo atractiva que es su esposa y se va separando de Adela. Finalmente los Marqueses se reúnen de nuevo y abandonan Madrid, Adela se consuela con la fortuna de Paniagua y Peñaflor queda decepcionado cuando se da cuenta de que la Marquesa le ha utilizado. Toda la acción se desarrolla en ambientes elegantes y Navarrete se complace en describir, bailes, salones, coches de caballos, vestidos femeninos y masculinos y ambientes exquisitos.

El camino abierto por Navarrete iba a ser seguido por muchos otros autores. En especial los últimos años del Semanario Pintoresco Español iban a abundar en relatos de estas características. Juan de Ariza publicaría en esa revista «Dos Flores y Dos Historias» (1848), «Amor a Vista de Pájaro» (1851), «Castillos en el Aire» (1851), «Dos Secretos» (1852) e «Historia de Amores» (1856). Agustin Bonnat es autor de «Por no saber nadar. Historia de unos Amores» (1853), «Nunca. Historia de unos Amores» (1854), «Un Nido de Tórtolas» (1854), «Un Nido Vacío» (1855), «Una Punta de Cigarro» (1855), «¡Vuelvo! Historia de unos Amores» (1855) y «Dos Ramos de Flores» (1856). Francisco de Espínola publica, en 1856, «i¡os Amores!!». Algo más tempranamente, Teodoro Guerrero y Pallarés contribuye al género con «Memorias de una Fea» (1847) y «Memorias de una Bella» (1848). «Rosalía» (1853) y «Un Amor Increíble» (1857) son obra de Florencio Moreno y Godino y «Amor al Uso» (1857) de Gabriel de Velasco. Sin compartir todas las características antes apuntadas de los cuentos de Navarrete, todas estas narraciones tienen muchos puntos en común con ella: historias amorosas estrictamente morales, finales felices, preferencia por los ambientes elegantes, protagonista masculino que abandona su vida de Don Juan gracias al amor de una joven, etc...

\section{CONClusión}

Las narraciones que aparecen en las tres revistas que hemos analizado en este artículo representan el triunfo de la modalidad más tradicional y conservadora del Romanticismo Español. Tanto los cuentos publicados en El Laberinto, como los de El Siglo Pintoresco y los de la Revista literaria de El Español, coinciden en temas, tratamientos y enfoques con 
los que se pueden encontrar en el Semanario Pintoresco Español. Por el contrario las tentativas más innovadoras e iconoclastas que en El Artista aparecían no tienen descendencia. En la década de 1840 hay un muy breve intento de mantener un tono de renovación en la narrativa, con la revista El Pensamiento, promovida por Espronceda y en la que aparecen muy interesantes relatos de dos autores profundamente originales como son Miguel de los Santos Álvarez y Antonio Ros de Olano. Pero el fracaso de la revista, que sólo publicó doce números entre mayo y octubre de 1841, abortó definitivamente la posibilidad de rumbos diferentes en la narración breve. De 1841 en adelante los cuentos que beben en la vertiente tradicionalista, histórica y conservadora del Romanticismo español dominan de forma abrumadora en el panorama de la narración breve española.

\section{BibliografíA}

FUENTES, J.F. y FERNÁNDEZ SEBASTIÁN, J., Historia del periodismo español, Madrid, Síntesis, 1997.

GÓMEZ APARICIO, Pedro, Historia del periodismo español. Desde la gaceta de Madrid hasta el destronamiento de Isabel II. Madrid, Editora Nacional, 1967.

MADRAZO Y KUNTZ, P. Cuentos. Introducción de B. Rodríguez Gutiérrez, Santander, Ediciones de la Universidad de Cantabria, 2004.

RODRÍGUEZ GUTIÉRREZ, B., «Cuento y drama romántico: El Lago de Carucedo», Hispanic Journal, 21-2 (2000), pp. 501-514.

RODRÍGUEZ GUTIÉRREZ, B., «La narración breve en tres revistas románticas: Observatorio Pintoresco (1837), El Panorama (1838-1841), La Alhambra (1839-1843)», Philologia Hispalensis, XV, (2001), pp. 189-208.

RODRÍGUEZ GUTIÉRREZ, B. «Los cuentos de la prensa romántica española (18301850). Clasificación temática», Iberoromania, 57, (2003), pp. 1-26

RODRÍGUEZ GUTIÉRREZ, B., Historia del cuento español (1764-1850), MadridFrankfort, Iberoamericana-Vervuert, 2004.

RUBIO CREMADES, Enrique, Periodismo y Literatura: Ramón de Mesonero Romanos y el Semanario Pintoresco Español, Alicante, Instituto Juan Gil-Albert, 1995.

SÁNCHEZ ARANDA, J. J. y BARRERA, C., Historia del periodismo español desde sus orígenes hasta 1975, Pamplona, Ediciones Universidad de Navarra S.A. 1992.

SEOANE, M. C., Oratoria y periodismo en la España del siglo XIX, Valencia, Editorial Castalia/Fundación Juan March, 1992.

SHAW, D. L., «El drama romántico como modelo literario e ideológico». Historia de la literatura española. Siglo XIX (I), Director de la obra: Victor García de la Concha. Coordinador del volumen: Guillermo Carnero, Madrid, Espasa Calpe, 1997, pp 314-351. 
.

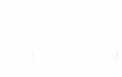

